\title{
Research on Making Tacit Knowledge Explicit
}

\author{
Hongling Guo \\ The school of public administration, The Southwest Jiaotong University, Chengdu 610031, China \\ hlg@swjtu.edu.cn
}

\begin{abstract}
This study attempts to bring some clarification to the ideas of tacit knowledge. The article reviews the definition of tacit knowledge in broader management literature and believes that it is frequently used definition with multiple meanings. The different categories of tacit knowledge proposed by researchers is discussed. And this study also distinguishes between how different types of tacit knowledge are transferred into explicit knowledge.

Index Terms - Tacit Knowledge, Explicit Knowledge, Converting
\end{abstract}

\section{I ntroduction}

In a knowledge-based economy, companies are increasingly realizing that their knowledge base is the basis of their competitive advantage [1]. Miroslav Rebernik et al (2007) argue the knowledge resources of organizations may be described as an iceberg. Structured, explicit knowledge is the visible top of the iceberg. Beneath the surface of conscious thought lies a vast sea of tacit knowledge, derived from a lifetime of experience, practice, perception and learning. They insisted the difficulty of expressing, codifying and transmitting tacit knowledge makes it easier for a company to protect it than explicit knowledge, and to be the basis of an inimitable competitive advantage.[2]

However, there is some confusion and debate over what tacit knowledge is, and is not, and whether or not it can be "captured or articulated .[3]

This study attempts to bring some clarification to the ideas of tacit knowledge. Firstly we review the related concepts of tacit knowledge. Then we discuss various categories of tacit knowledge that have been proposed by researchers. Finally, we summarize the method of making different types of tacit knowledge explicit.

\section{What Is Tacit Knowledge?}

Definitions for tacit knowledge vary in the difference literatures. The research on tacit knowledge originated from philosophy. In 1958, The famous philosopher, Polanyi used the conception of tacit knowledge to emphasis on the cognitive process. Later, the phrase 'tacit knowledge' is used in a wide range of disciplines. The different scholars hold different perspective from different aspects.

From knowledge management, Nonaka and his colleagues insisted tacit knowledge is a non-linguistic non- numerical form of knowledge that is highly personal and context specific and deeply rooted in individual experiences, ideas, values and emotions[4].And they also distinguished between technical tacit knowledge and cognitive tacit knowledge[5]. Baumard (1999) has provided the most extensive treatment of tacit knowledge in a knowledge management and organizational context. He claimed tacit knowledge is that the people are not aware of having learned, or that they actually possess. He distinguished two types of organizational knowledge that "cannot be articulated or stabilized" - implicit knowledge, and tacit knowledge [6]. But Hazel Taylor (2007) insisted they actually are same thing. He thought implicit or tacit knowledge is knowledge that a person may be unaware of having, and that is difficult to articulate.[7]

From AI, Janik(1988) argued tacit knowledge have two sense: first, to refer to knowledge that could be made explicit, but which haven't been so rendered; second, to the aspects of human experience which are wholly knowable selfreflectively, but are incapable of precise articulation.

From the sociology of scientific work, Collins and his colleagues, defined tacit knowledge as "knowledge or abilities that can be passed between scientists by personal contact but cannot be, or have not been, set out or passed on in formula, diagrams, or verbal descriptions and instructions for action'." [8]

Aadne et. al. (1996:12, 24) saw tacit knowledge not only as personal, but also residing in individual and social relationships in the firm. They suggest the tacit knowledge could transfer between organizations. But Von Krogh and Roose(1995) argued strongly that tacit knowledge is a characteristic of individuals alone, and cannot be communicated (von Krogh \& Roos 1995: 50-51).

Sternberg et al. (2000) argue tacit knowledge is a practical intelligence which the person acquired implicitly from everyday experience. It is difficult for the possessor to articulate or explain what he knows. This tacit knowledge has three features. The first feature is the knowledge that a person gains by experience, by observation, and trial and error without systematic support from other people or media (e.g., books). The second feature is that practical intelligence tends to be procedural, procedural knowledge is generally considered to be related only to skills acquisition. It is knowledge that guides behavior. The third feature is practical intelligence has a direct practical outcome which may be of use to the person in his or her work situation, or in social and personal settings.[9]

From above, it shows that scholars reached some basic consensus on some characters of tacit knowledge despite existing diversity of viewpoints.

Firstly, tacit knowledge can root in individual and collective. The two carriers are connected with each other without doubt. But soever carrier, Tacit knowledge is difficult to describe and transmit to others. And it is closely related to personal experience and contextual.

Secondly, tacit knowledge remains hidden, unspoken, it can either embodied in people and social networks or 
embedded in the processes and products that people create [10]. Tacit knowledge is difficult to be extracted without the consent of the knowledge owner. And it tends to be local as well as stubborn because it is not found in manuals, books, databases or files.

Thirdly, tacit knowledge is the source of competitive advantage and innovation of firms, as well as being critical to daily management activities, because it is difficult to imitate and acquire. The difficult to expressing, codifying and transmitting tacit knowledge makes it easier for accompany to protect it than explicit knowledge. Moreover, tacit knowledge may only be effective when embedded in a particular organizational culture, structure and set of processes and routines. So, managers usually encourage employees to share their tacit knowledge in order to enhance organizational competitiveness.

\section{The Classification of Tacit Knowledge}

For further understanding of tacit knowledge, researchers have distinguished different types of tacit knowledge from different aspects. Polanyi (1966) insisted that all knowledge has tacit dimensions.

Leonard and Sensiper (1998) argued tacit knowledge can be completely tacit, semiconscious or unconscious knowledge held in peoples heads and bodes. Based on the above, they classified tacit knowledge into two dimensions: technical and cognitive. As Leonard \& Sensiper(1998) saying, tacit knowledge embodied in physical skills resides in the bodes muscles, nerves and reflexes and is learned through practice. And tacit knowledge also embodied in cognitive skills. Technical tacit knowledge is skills know-how. It is usually not possible for individual to articulate or describe [10]. Hsia(1993) claimed technical encompasses information and expertise in relation to "know-how", while cognitive consists of mental models, beliefs and values. These mental models are so ingrained that we take them for granted. At some time, experts can be asked to articulate their cognitive tacit knowledge, their explanations maybe more related to what they think ought to underpin their knowledge, rather than what actually does as they do not really know at a conscious level why they choose certain actions.

From owners of tacit knowledge, Miroslav et al (2007) classified tacit knowledge into three different level including individual and organizational as well as contexts. At the individual level, they think that people experience tacit knowledge mostly as intuition, rather than as a body of facts or instruction sets he or she is conscious of having and can explain to others. It has to be internalized in the human body and soul. At the organizational level, they argued tacit knowledge rooted in organizational memory, while organizational memory is not just explicit knowledge that is captured, but importantly, it also has a tacit dimension. On an context level, tacit knowledge can exist in organization's deep-seated underlying values and belief systems that guide, shape and dictate the individual's everyday attitudes and behaviors.
Other researchers argue tacit knowledge in organization and the context level may be called collective tacit knowledge which is held by a group or an organization rather than a single individual. So, tacit knowledge can be classified into individual and collective tacit knowledge.

Ambrosini and Bowman (2001) differentiate three levels of implicitness of an individual tacit knowledge include in non-epistle, sagacious and semantic tacit knowledge. The nonepistle tacit knowledge is the result of implicit learning and is completely in-articulable, and it is unlikely to be explicitly transferable to other individuals [11]. Sagacious knowledge is a tacit form of knowing that "emanates in an acute and keen practical sense". This knowledge is accessible through metaphor and analogy. The third level of tacit knowledge is semantic knowledge. It is often discerned in conversations between experts, who share a common technical foundations and abstract expressions of their expert area, and thus never explicitly discuss basic terminology and definitions.[12]. While collective tacit knowledge may be thought of as "the way we do things round here." Although individual members in the organization can articulate much of this knowledge, it has not been formally captured and recorded in the group's explicit knowledge repository, and thus it remains at the implicit level for the group as a whole.(Hazel Taylor,2007). Blackler defined a further subset of collective tacit knowledge into uncultured knowledge, which refers to the knowledge about the cultural or social norms regarding how to behave or interact with others in the group in given situations. Individuals usually learn enculturated knowledge implicitly as part of an on-going socialization process. But the rule will can change with social context.

Lubit insisted there are four categories of tacit knowledge[13] (p.166):

(1)Hard-to-pin-downslides. Know-how", the word skill implies tacit knowledge. People need to repeatedly practice skills, receive feedback and get a feel for them.

(2) Mental models. We draw on mental models or schema when trying to make sense of a situation; they determine how we understand and analyse situations; that is, how we understand cause-effect connections and what meaning we attribute to events.

(3)Ways of approaching problems. Tacit knowledge underlies the decision trees people use.

(4) Organizational routines. Much of a firm's tacit knowledge is stored in its routines. This tacit knowledge embedded in routines includes an intuitive grasp of what data to focus on and of the relative priority of competing demands. In time, managers leave and the routines remain as a legacy of their knowledge.

It is thus clear that tacit knowledge have been differentiated different types because of the researchers' different goal. These different classification showed diversified features of tacit knowledge, which can help us gain some deep insight into the nature of tacit knowledge, and find different ways to make tacit knowledge explicit. 


\section{Methods of Making Tacit Knowledge Explicit}

It is important that tacit knowledge be converted to explicit knowledge for any organization. In recent years, tacit knowledge transformation has been the focus of a wide range of studies in some disciplines .As Nonaka and Takeuchi (1995) saying, tacit knowledge has little value until it can be converted into explicit knowledge that other members can share (Nahapiet \& Ghoshal, 1998). Some scholars explore the methods to convert different types tacit knowledge.

From classification of technical and cognitive tacit knowledge, Takeuchi (2001) believed Technical tacit knowledge can be transferred by nonverbal means such as apprenticing to an expert, being mentored by an expert, or observation and behavior modeling. While Cognitive tacit knowledge is knowledge that is developed implicitly using "mental models" exemplar situations. [14]

Leonard and Sensiper(1998) also stated tacit knowledge grows through shared observation and from mimicking behavior, especially by collaboratively problem solving. In the process of conversation, incentives, motivation, and a "cultural foundation for knowledge management" are the critical success factor.[15]

Anderson (1982) proposed a framework for learners' skill acquisition. At the first stage, learners get the knowledge of the facts and procedures that are required in order to perform the skill. They know "what to do". At this stage learners may not be able to demonstrate the skill in practice. At the procedure knowledge stage(the second stage), the learners know "how to do" by actual practice of the skills. Actually they can integrate the knowledge from the first stage and the second stage. When the skill can be done more and more automatically, without thinking, the learners can create some new skill and gain some new cognitive about the skill which become new tacit knowledge.[16]

Many scholars explored the conversion ways of tacit knowledge from the different owners. From the perspective of individual and collective tacit knowledge, some researchers insist that individual tacit knowledge can be converted to explicit knowledge by "reelection in action" (Schon 1983), or by using mentoring and storytelling (Swap, Leonard, Shields \& Abrams, 2001), or by social interaction (Nanaka \& Takeuchi,1995), or by using metaphor, analogy, graphical presentation, and/or body language. However, although it is possible to "externalize" some parts of tacit knowledge, some aspects of tacit knowledge, particularly those related to creativity, intuition, and skill performance, are unlikely to ever be made completely explicit (Leonard \& Sensiper, 1998; Tsoukas, 2003). For collective tacit knowledge, which manifested in social interactions and shared understandings of social norms and behaviors, may be transferred mainly by "socialization"---observation and informal behavior modeling or by direct explanation of the rule in a particular context. While the collective tacit knowledge which resides in systemic routines can be transferred informally by observation and by on-the-job training of "the way we do things round here."

For the tacit knowledge in individual level, Baumard (1999) proposed formal interviews are a useful method of transforming. Outside observers can assist in the knowledge conversion process by asking employees a series of structured questions. For example, how do you interact with your environment? From where do you draw your knowledge? What knowledge gives you a major advantage? Do you know thing that others in the organization do not know? But these questions should be asked in at least two different interviews so that the observations are accurate and should not impose the employees as the sole "articulator of tacit knowledge".[17]

For the collective tacit knowledge, Nonaka and Takeuchi (1995) propose four modes of knowledge transfer: socialization; externalization; internalization; and combination. In the modes, internalization means the conversion of explicit knowledge into tacit knowledge, through practicing process or learning by doing. Externalization is the conversion of tacit knowledge to explicit knowledge by using metaphor, analogy, graphical presentation, and/or body language. Socialization indicates members in the organization sharing tacit knowledge with each other via group interaction and participation. Lastly, combination is the transforming of existing explicit knowledge through the process of systemization, integration, and circulation, to become more a complicated form for further use.They also discussed the importance of building a self-organizing team, sharing experience, and conceptualization in the process of tacit knowledge externalization.[18]

Durrance(1998) proposed four points of sharing of tacit knowledge in the organization, including watching, allowing time for reflection and interpersonal exchange in any training exercise. Davenport (2001) argued that "communities of practice", a flexible informal organization, often generates links between individuals who can provide useful information by storytelling, collaboration, and social construction.

In the collective of organization level, Nonaka et al.(2001) argued it is a effective conversion method through interacting with others. Especially, it is important for tacit knowledge sharing that the teams work together in a complimentary manner through collaborative relationships, informal conversations, and formal information transfer.[19]

Researches have shown that Tacit-to-explicit exchange is greatly enhanced by close personal contact. So physical colocation and face-to-face interaction can be important catalysts for sharing tacit knowledge. The frequent use of brief "tandup-meetings", for example, can help ensure continuous interaction among team members and encourage socialization and collaboration in transformation tacit knowledge activities

\section{Conclusion}

Tacit knowledge is an appealing concept that people intuitively understand but it is often used loosely and imprecisely ( Hazel Taylor,2007) .The scholars reached some basic consensus on tacit knowledge despite existing diversity of viewpoints. Firstly, Tacit knowledge is closely related to personal or collective experience and contextual, and it is difficult to describe and transmit to others. Secondly, it is the source of competitive advantage and innovation of firms. 
Thirdly, we can classify tacit knowledge into different categories from different perspective. And every types of tacit knowledge can have different characteristics. Finally, tacit knowledge can be share and come into play only when it can be converted into explicit knowledge. We can adopt different method of making tacit knowledge explicit according to different types. It is necessary to explore how to put into use these conversion method and which method is more effective.

\section{References}

[1] Sveiby, K.E.(1997). The new organizational wealth: Managing and measuring knowledge based assets. San Francisco: Berrett-Koehler.

[2] Miroslav Rebernik \& Karin Sirec "Fostering innovation by unlearning tacit knowledge" Kybernetes Vol.36No.3/4, 2007 pp.406-419.

[3] Castillo, J. (2002). A note on the concept of tacit knowledge. Journal of Management Inquiry, 11(1), 46-59.

[4] Nonaka, I. 1991, "The knowledge-creating company". Harvard Business Review. (November- December):96-104.

[5] Nonaka, I. and Takeuchi, H. 1996, "A theory of organizational knowledge creation." International Journal of Technology Management, Special Issue on Unlearning and Learning for Technological Innovation. 11(7/8):833-845.

[6] Baumard, P. 1999 Tacit knowledge in organizations, London \& Thousand Oaks: Sage.

[7] Hazel Taylor,(2007)“Tacit Knowledge: conceptalizations and operationalizations" International Journal of Knowledge Management 3(3),60-73.

[8] Collins, H. M., 2001a, "What is tacit knowledge?," Chapter 7 in : Schatzki, T. R.; Knorr Cetina, K., and von Savigny, E., (eds). The practice turn in contemporary theory. London and New York: Routledge; pp. 107-119.
[9] Sternberg, R. J., Forsythe, G. B., Hedlund, J., Horvath, J. A., Wagner, R. K., Williams, W. M., et al. (2000). Practical intelligence in every day life. Cambridge: Cambridge University Press.

[10] Horvath, J.A. (2007). Working with Tacit Knowledge. IBM Institute For Knowledge Management.

[11] Leonard, D., \& Sensiper, S. (1998). The role of tacit knowledge in group innovation. California Management Review, 40(3), 112-132.

[12] Ambrosini, V., \& Bowman, C. (2001). Tacit knowledge: Some suggestions for operationalization. Journal of Management Studies,38(6), 811-829

[13] Castillo, J. (2002). A note on the concept of tacit knowledge. Journal of Management Inquiry, 11(1), 46-59.

[14] Lubit,R.(2001), 'The keys to sustainable competitive advantage :tacit knowledge and knowledge management" Organizational Dynamics, Vol.29 No.3, pp.164-78.

[15] Takeuchi, H. (2001). Towards a universal management of the concept of knowledge. In I. Nonaka \& D. J. Treece(Eds.), Managing industrial knowledge: Creation, transfer and utilization London: Sage.

[16] Casonato \& Harris,1999, "Can an enterprise really capture "tacit knowledge":we answer two top questions on knowledge management from the electronic workshop 1999 conference" Gartner group research note select Q\&As

[17] Anderson, J. R. (1982). Acquisition of cognitive skill. Psychological Review, 89(4), 369-406.

[18] Baumard, P,(1999), Tacit knowledge in organizations, Sage publications, thousand oaks, CA.

[19] Nonaka, I., \& Takeuchi, H. (1995). The knowledge creating company how Japanese companies create the dynamics of innovation. New York: Oxford University Press.

[20] Nonaka, I., Toyama, R., \& Konno, N. (2001). SECI, Ba of dynamic knowledge creation. In I. Nonaka \& D. J. Treece (Eds.), Managingindustrial knowledge: Creation, transfer and utilization. London: Sage. 